\title{
Experimental and Analytical Study on Reinforced Concrete Beams in Bending Strengthened with FRP
}

\author{
C.C. Spyrakos ${ }^{1, *}$, I.G. Raftoyiannis ${ }^{1}$, L. Credali ${ }^{2}$ and J. Ussia ${ }^{2}$ \\ ${ }^{l}$ Civil Engng Dept., National Technical University of Athens, Greece; ${ }^{2}$ Ardea e Sistemi S.r.l., Bolonia, Spain
}

\begin{abstract}
The performance of the interface between fiber reinforced polymer (FRP) composites and concrete is one of the key factors affecting the behavior of strengthened reinforced concrete (RC) structures. Existing laboratory research has shown that RC beams strengthened with FRP sheets usually fail because of either debonding of the impregnated fabric from the concrete substrate or fracture of the FRP. This work presents an experimental and analytical investigation of the effectiveness of FRP strengthening sheets on RC beams aiming at increasing their flexural strength and stiffness. Experimental results obtained from beam specimens tested under four-point bending are examined with main parameters being the resin type and the anchoring system. In addition, the procedure suggested by the EC 8 - Greek Assessment \& Retrofitting Code (EC8-GARC) provisions is applied and compared with the experimental results.
\end{abstract}

Keywords: Anchoring systems, assessment of FRP design codes, concrete beam testing, FRP debonding, FRP failure modes, FRP strengthening.

\section{INTRODUCTION}

External bonding of FRP composites constitutes a popular technique to strengthen concrete structures worldwide. Two types of debonding failure are commonly observed in strengthened RC members: sheet-end and intermediate crack induced debonding. In order to understand and develop methods to predict such debonding failures, the bond behavior between concrete and FRP has been widely studied using simple shear tests on FRP plate/sheet-to-concrete bonded joints and a great deal of research results is now available However, for intermediate crack induced debonding failures, the debonding behavior can significantly differ from that observed in a simple shear test. Among other factors, the most significant difference may be the fact that between two adjacent cracks the FRP is subjected to tension at both cracks.

Teng et al. [1] presented an analytical model for the debonding process of an FRP-to-concrete bonded joint model where the FRP is subject to tension at both ends. Subramaniam et al. [2] studied the influence of the width of FRP sheets on the load-carrying capacity of RC beams for shear debonding. Chen and Qiao [3] presented a cohesive interface modeling approach for debonding analysis of adhesively bonded interface between two adjacent flexural cracks in concrete beams strengthened with externally bonded FRP plates. Chen et al. [4] presented a simplified analytical solution for the debonding failure along a softening FRP-toconcrete interface between two adjacent cracks in concrete members. Gunes et al. [5] studied, experimentally and analytically, debonding failures of FRP strengthened RC beams. Ombres [6] studied the debonding failure modes on FRPstrengthened $\mathrm{RC}$ beams using a nonlinear local deformation model derived from crack analysis based on slip and bond

\footnotetext{
*Address correspondence to this author at the Civil Engng Dept., National Technical University of Athens, Greece; Tel: 00302107721180; Fax: 00302107721182; E-mail: cspyrakos@central.ntua.gr
}

stresses. Benzarti et al. [7] presented a damage model to predict the durability of bonded assemblies and particularly the debonding behavior of FRP strengthened concrete members. Ceroni et al. [8] presented a brief overview of anchorage systems by introducing experimental tests on several types of end-fixing for reinforced polymers (FRP) sheets glued on RC elements. Bruno et al. [9] proposed a refined model able to analyze edge-mixed-mode debonding problems of beams strengthened with externally bonded composite laminated plates, where the structural system consisted of a base beam, an adhesive layer and a bonded FRP plate. Casas and Pascual [10] presented a simplified model and an experimental validation for debonding of FRP strengthend $\mathrm{RC}$ beams in bending.

Beams under four-point bending tested by Alagusundaramoorthy et al. [11] failed because of reinforcement yielding in tension before the concrete compression strain reached the limit of $0.3 \%$. Bending cracks in the area between the two concentrated loads were observed in all beams tested either prior or after strengthening. The majority of beams strengthened with CFRP sheets failed because of concrete compression at one of the concentrated loading positions. Upon the beginning of concrete compression, separation of FRP sheets was also observed.

The RC beams tested by Takeda et al. [12] developed bending cracks and finally failed in compression of concrete. The strengthened beams also developed bending cracks, but failed in rupture of the carbon FRP sheets. Takeda et al. [12] concluded that by increasing the number of FRP sheets the flexural stiffness and strength increased, while the strain capacity decreased. The beam that was already loaded before being strengthened, after comparing it to a similar one strengthened with identical carbon FRP, a similar behavior was observed. Thus, it was concluded that the effect of initial loading on the flexural behavior of strengthened beams is negligible. 
Kim and Shin [13] studied the flexural behavior of beams strengthened with different types of FRP sheets. Beams on which a glass FRP sheet was applied first, demonstrated higher strength and stiffness compared to the others. They also reported that the consequences on preloaded beams can be easily overcome by retrofitting the cracks (resin fill) before the application of composite materials.

Norris et al. [14] stressed the fact that the increase of strength and stiffness as well as the failure mode depend on fiber direction. When the orientation of carbon fibers is perpendicular to the cracks, the strength and stiffness increase is larger and concrete failure occurs because of stress concentration about the edge of the composite material. When the fibers are applied at an angle of $45^{\circ}$ to the cracks, the strength and stiffness increase are smaller but the failure mode is still the same as before.

Regarding FRP anchorage, Demakos and Dimitrakis [15] concluded that U-shape sheet anchorage led to higher stiffness for beams compared to those on which carbon fiber anchors were applied. Additionally, beams with one anchor at each end were more flexible than those with two anchors at each end. In any case, the beams with two anchors at each end failed at a higher load [16]. In general, all beams demonstrated a flexural failure mode and minor compression cracks on the upper side. The group of beams with the U-shape sheet anchorage exhibited the following behavior: for two out of three beams the sheet detached from the middle section, while for the third the sheet detached from the left-end section. The response of beams with one anchor at each side was practically the same, apart from the fact that one of these beams developed flexuralshear cracks. The FRP sheet applied on beams with two anchors at each side was ruptured at either the middle or the left-end section and the beams showed significant increase in their stiffness [17-19].

Regarding the most widely used codes and provisions, one could refer to the International Federation for Structural Concrete (FIB) [20], the Italian Code (CNR-DT 200/2004)
[21] and the AC8-Greek Assessment and Retrofitting Code [22]. As elaborated in these codes and the international literature, the failure modes for a beam in flexure, shown in Figs. 1(a) and 1(b), are: 1) excess of the maximum compressive strain in the concrete compression zone, 2) tensile failure in the laminate, 3 ) peeling failure at the laminate cut-offend against concrete beam, 4) delamination in the laminate, 5) the steel reinforcement yield in tension, 6) the steel reinforcement yields in compression, and 7) anchorage failure in the bond zone of the laminate. The first four, as primarily brittle failures, should be avoided.

The present work presents the results of an experimental and analytical study on RC beam strengthening with FRP sheets aiming at increasing its flexural strength and stiffness. The results are evaluated according to experimental, analytical and design code procedures provided in the international bibliography.

\section{EXPERIMENTAL PROGRAM}

\subsection{Description of the Specimens and Testing Set-Up}

Four-point bending tests were conducted at the Laboratory for Earthquake Engineering (LEE) at the National Technical University of Athens (NTUA). The tests were performed on four full-scale reinforced concrete beams strengthened with externally bonded FRP. The main purpose of the experimental research was to investigate the response of strengthened beams (strength, deflection, failure modes) both experimentally and analytically. This section presents the test results and the main conclusions derived from the experiments. Table 1 presents the reinforced concrete beam specimen data. Tables $\mathbf{2}$ and $\mathbf{3}$ provide the carbon sheet, the epoxy and the IPN resin data. Figs. $\mathbf{2}$ and $\mathbf{3}$ show the geometry and the reinforcement details of the specimens.

Regarding the CFRP testing, Table 4 presents data on the specimens.

The installation of the carbon FRP (CFRP) sheets involves the following steps: a) beam surface cleaning, b)

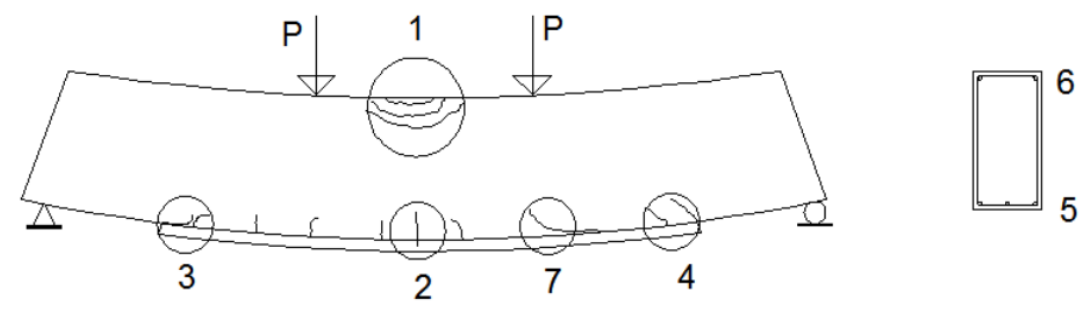

Fig. (1a). FRP flexural strengthening - Failure modes.

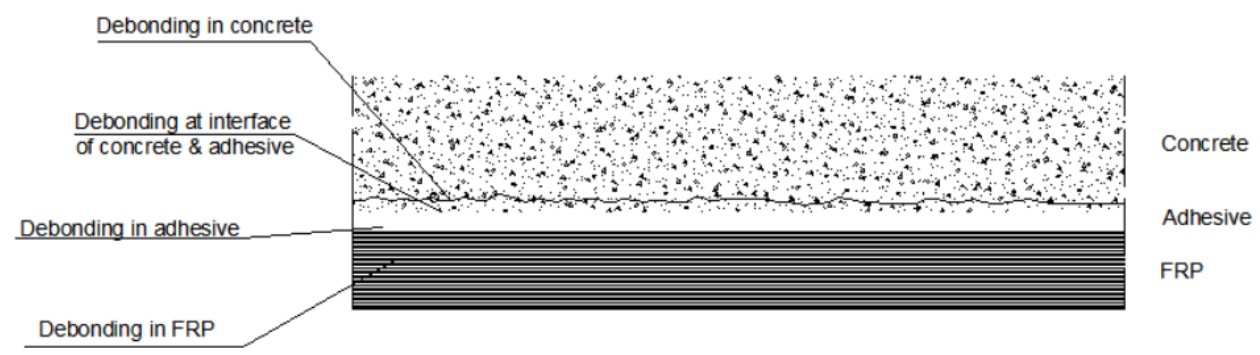

Fig. (1b). Debonding between concrete and FRP. 
smoothing of beam edges to create appropriate curvature, c) launching of water under pressure and then drying the concrete surface until the beam moisture is $<4 \%$, d) coating of concrete application area with resin, and e) application of FRP sheets. When the ARDFIX system was applied, the anchors were placed prior to step (e) by proper drilling and use of $5 \mathrm{~cm}$ carbon strips as shown in Figs. 4(a) and 4(b).

Table 1. Concrete section no 1 data.

\begin{tabular}{|c|c|c|}
\hline $\begin{array}{c}\text { Beam Section (Height } h- \\
\text { Width b) }\end{array}$ & $50 \mathrm{~cm} x$ & $25 \mathrm{~cm}$ \\
\hline $\begin{array}{c}\text { Concrete average compres- } \\
\text { sive strength }\end{array}$ & $\mathrm{f}_{\mathrm{cm}}=$ & $20 \mathrm{MPa}$ \\
\hline Steel type & & S500 \\
\hline Steel Modulus of Elasticity & $\mathrm{E}_{\mathrm{s}}=$ & $200 \mathrm{GPa}$ \\
\hline Compression reinforcement & $2 \Phi 14$ & $\mathrm{As}^{\mathrm{com}}=3.079 \mathrm{~cm}^{2}$ \\
\hline Tension reinforcement & $2 \Phi 14$ & $\mathrm{Ast}^{\mathrm{en}}=3.079 \mathrm{~cm}^{2}$ \\
\hline $\begin{array}{c}\text { Transverse reinforcement } \\
\text { diameter }\end{array}$ & $\Phi_{\mathrm{w}}=$ & $8 \mathrm{~mm}$ \\
\hline $\begin{array}{c}\text { Compression reinforcement } \\
\text { diameter }\end{array}$ & $\Phi_{\mathrm{Lt}}=$ & $14 \mathrm{~mm}$ \\
\hline $\begin{array}{l}\text { Tension reinforcement } \\
\text { diameter }\end{array}$ & $\Phi_{\mathrm{Lb}}=$ & $14 \mathrm{~mm}$ \\
\hline Concrete cover & $\mathrm{c}=$ & $2.00 \mathrm{~cm}$ \\
\hline Beam length & $1=$ & $4.5 \mathrm{~m}$ \\
\hline $\begin{array}{l}\text { Distance of tension rein- } \\
\text { forcement from edge }\end{array}$ & $\mathrm{d}_{\mathrm{b}}=\mathrm{c}+\Phi_{\mathrm{w}}+0.5 \Phi_{\mathrm{Lb}}=$ & $3.50 \mathrm{~cm}$ \\
\hline $\begin{array}{l}\text { Distance of compression } \\
\text { reinforcement from edge }\end{array}$ & $\mathrm{d}_{\mathrm{t}}=\mathrm{c}+\Phi_{\mathrm{w}}+0.5 \Phi_{\mathrm{Lt}}=$ & $3.50 \mathrm{~cm}$ \\
\hline
\end{tabular}

Table 2. Carbon sheet data.

\begin{tabular}{|c|c|c|}
\hline Modulus of Elasticity & $\mathrm{E}_{\mathrm{j}}=$ & $240 \mathrm{GPa}$ \\
\hline Characteristic value of tensile strength & $\mathrm{f}_{\mathrm{fuk}}=$ & $3500 \mathrm{MPa}$ \\
\hline Characteristic value of ultimate strain & $\varepsilon_{\mathrm{fuk}}=$ & $1.5 \%$ \\
\hline Thickness of fabric & $\mathrm{t}_{\mathrm{j}}=$ & $0.17 \mathrm{~mm}$ \\
\hline Width of fabric & $\mathrm{w}_{\mathrm{j}}=$ & $0.20 \mathrm{~m}$ \\
\hline Number of layers of fabric & $\mathrm{n}_{\mathrm{j}}=$ & 3 \\
\hline
\end{tabular}

Table 3. Epoxy and IPN resin data.

\begin{tabular}{|c|c|c|}
\hline \multirow{2}{*}{ Modulus of Elasticity } & $\mathrm{E}_{\mathrm{RC}}=$ & $2.50 \mathrm{GPa}$ \\
\cline { 2 - 3 } & $\mathrm{E}_{\mathrm{IPN}}=$ & $3.00 \mathrm{GPa}$ \\
\hline \multirow{2}{*}{ Elongation at Break } & $\varepsilon_{\mathrm{RC}}=$ & $2.8-3.0 \%$ \\
\cline { 2 - 3 } & $\varepsilon_{\mathrm{IPN}}=$ & $1.2-2.5 \%$ \\
\hline
\end{tabular}

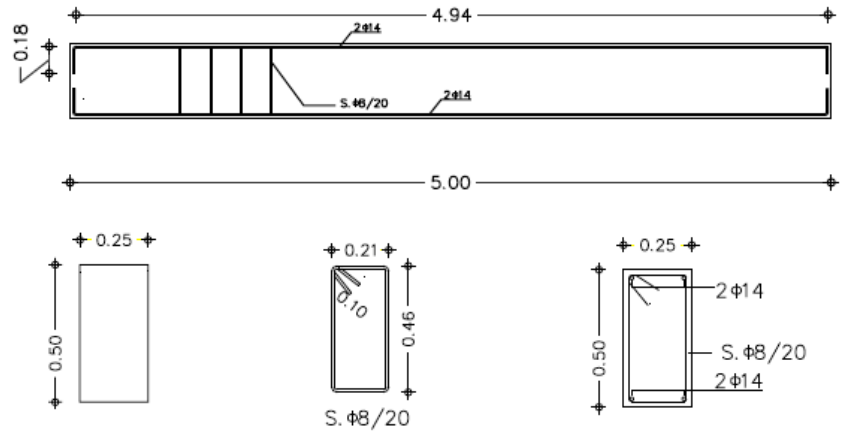

Fig. (2). Geometry and reinforcement details of tested beams.

0)

1)

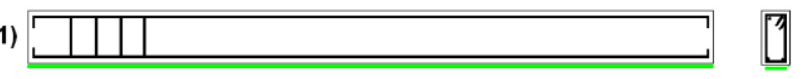

$\begin{array}{rrrr}0,40 & 0,40 & 0,40\end{array}$

2)

3) $\stackrel{0.20}{+0.40,0.40}+$

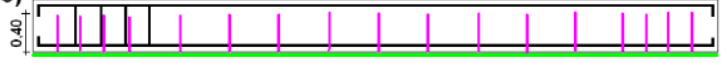

4)

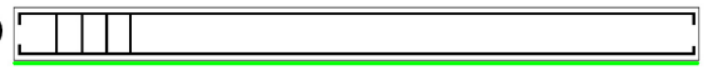

Fig. (3). Strengthened RC specimens.

Table 4. Data on the specimens.

\begin{tabular}{|l|l|}
\hline Specimen 0: & Concrete beam without the FRP strengthening system. \\
\hline \multirow{3}{*}{ Specimen 1: } & $\begin{array}{l}\text { FRP strengthening system with } 3 \text { layers of BETONTEX } \\
\text { GV330-U-HT, } \\
\mathrm{w}_{\mathrm{j}}=200 \mathrm{~mm} \text { carbon sheets, resin type: BETONTEX } \\
\text { RC01-RC02, no ARDFIX connector. }\end{array}$ \\
\hline \multirow{3}{*}{ Specimen 2: } & $\begin{array}{l}\text { Strengthening system with 3 layers of BETONTEX } \\
\text { GV330-U-HT, } \\
\mathrm{w}_{\mathrm{j}}=200 \mathrm{~mm} \text { carbon sheets, resin type: BETONTEX } \\
\text { RC01-RC02 and U-Shape ties. }\end{array}$ \\
\hline Specimen 3: & $\begin{array}{l}\text { Strengthening system of with 3 layers of BETONTEX } \\
\text { GV30-U-HT, } \\
\mathrm{w}_{\mathrm{j}}=200 \mathrm{~mm} \text { carbon sheets, resin type: BETONTEX } \\
\text { RC01-RC02 with ARDFIX connectors. }\end{array}$ \\
\hline Specimen 4: & $\begin{array}{l}\text { Strengthening system with 3 layers of BETONTEX } \\
\text { GV330- U-HT, } \\
\mathrm{w}_{\mathrm{j}}=200 \mathrm{~mm} \text { carbon sheets, resin type: BETONTEX } \\
\text { IPN01-IPN02, no ARDFIX connectors. }\end{array}$ \\
\hline
\end{tabular}

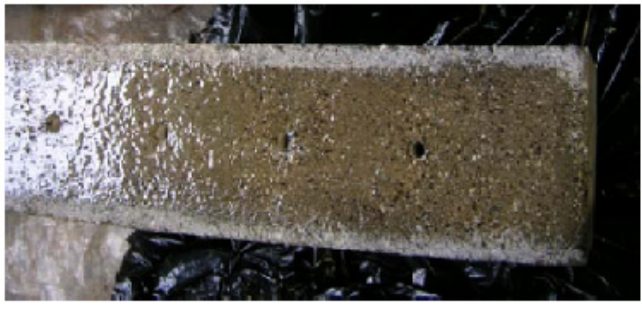

Fig. (4a). Drilling and placing of anchors. 


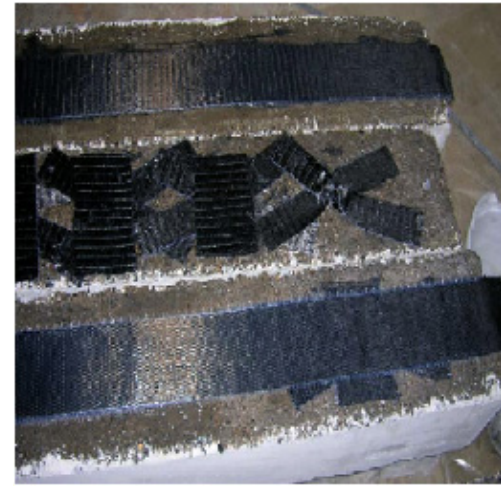

Fig. (4b). Placing of anchors and CFRP application.

\subsection{Test Results}

All specimens were tested in four-point bending up to failure. The experimental set-up is shown in Fig. 5. The load-deflection curves obtained for each specimen are presented in Fig. 6. The positions of the deflection meters are indicated as D1, D2 and D3 in Fig. 5(c).

\subsection{Observed Modes of Failure}

For specimen 1, debonding failure between FRP and concrete along the length of beam was observed. Also, flex- ural cracks developed at mid-span of the beam as shown in Figs. (7 and 8).

For specimen 2 flexural cracks at mid-span of the beam were observed. The test stopped when failure and breaking of U-Shape ties of carbon fibers and debonding from concrete were observed as shown in Figs. (9 and 10).

For specimen 3, flexural cracks at mid-span of the beam were observed (Fig. 11). The test ended when rupture of the carbon reinforcement at mid-span of the beam occurred (Fig. 12). During this test, no debonding between FRP and concrete was practically observed.

For specimen 4, small horizontal cracks were initially observed at both ends of the beam. With load increase, flexural cracks developed and propagated upwards in the region of high bending moment, that is, between the points of application of the concentrated loads to the beam. The test stopped when debonding of the CFRP sheets from concrete was observed, as shown in Figs. (13 and 14). No delamination among the composite layers appeared, attributed to their good impregnation with the IPN resin.

\section{ANALYSIS AND COMPARISON WITH CURRENT DESIGN PROVISIONS}

As a next step, using equilibrium and compatibility requirements, the strains, stresses and forces developed to the

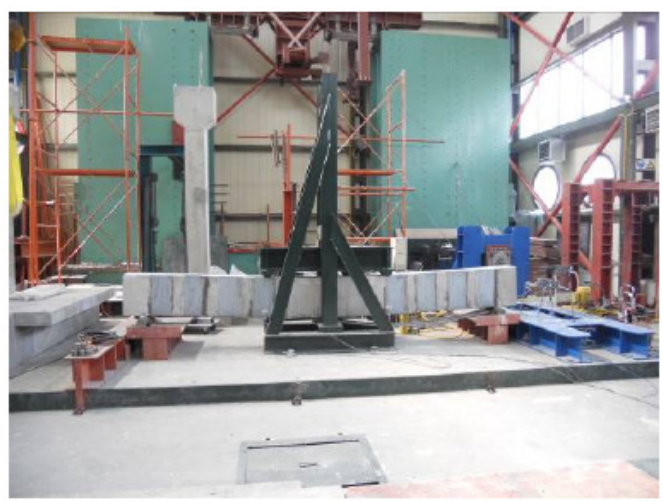

(a)

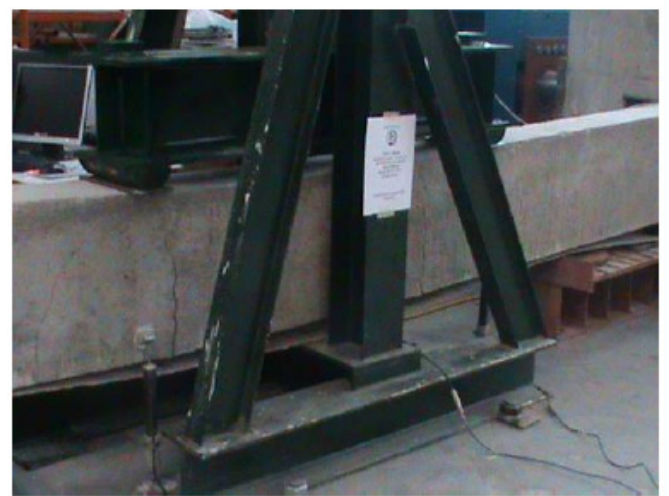

(b)

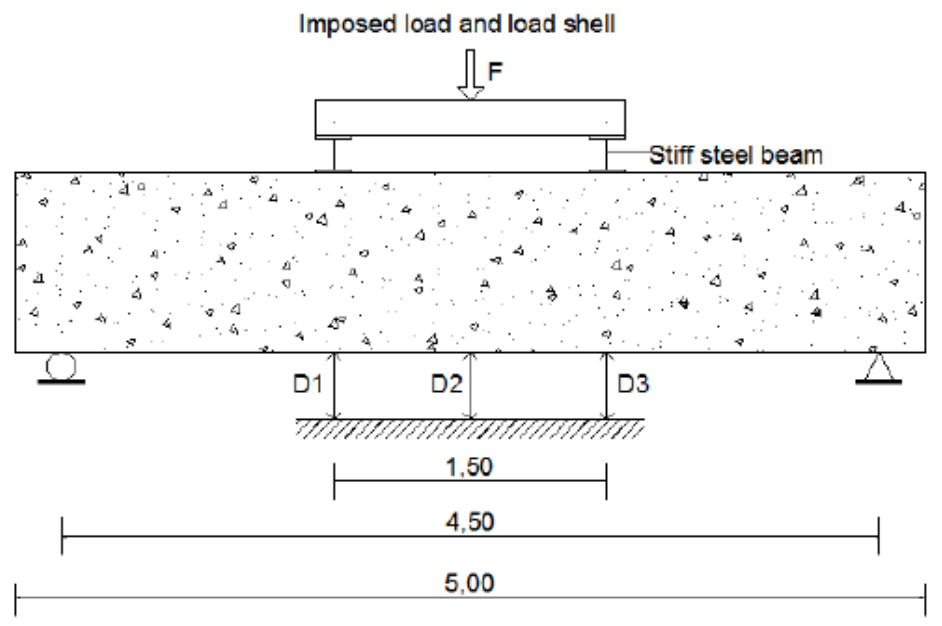

(c)

Fig. (5). Experimental setup (a) general view, (b) detail and (c) drawing. 


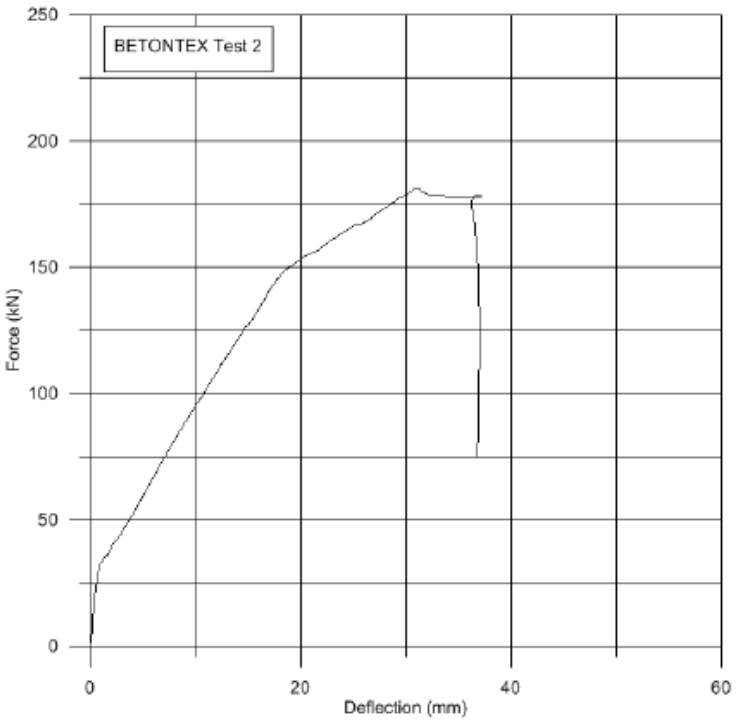

(a) Specimen 1

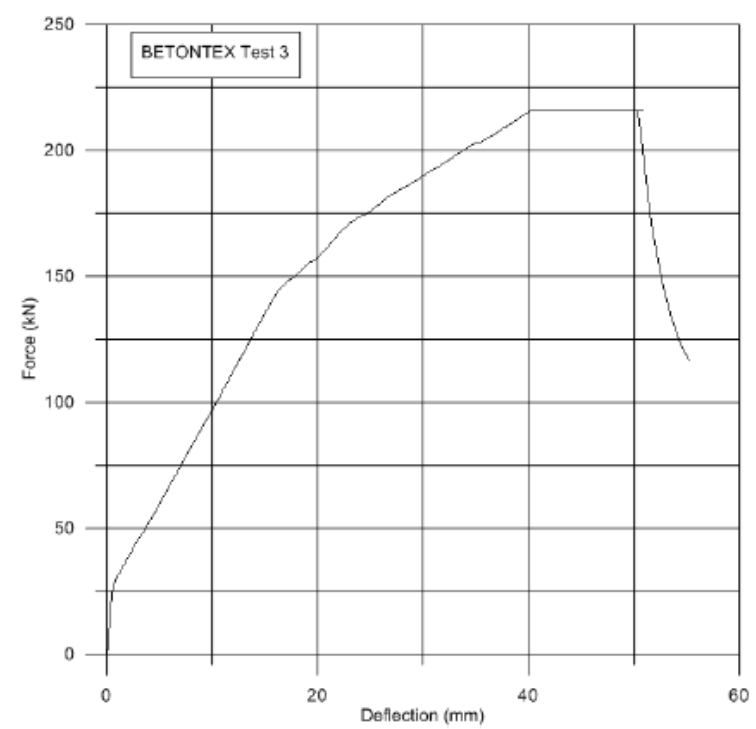

(c) Specimen 3

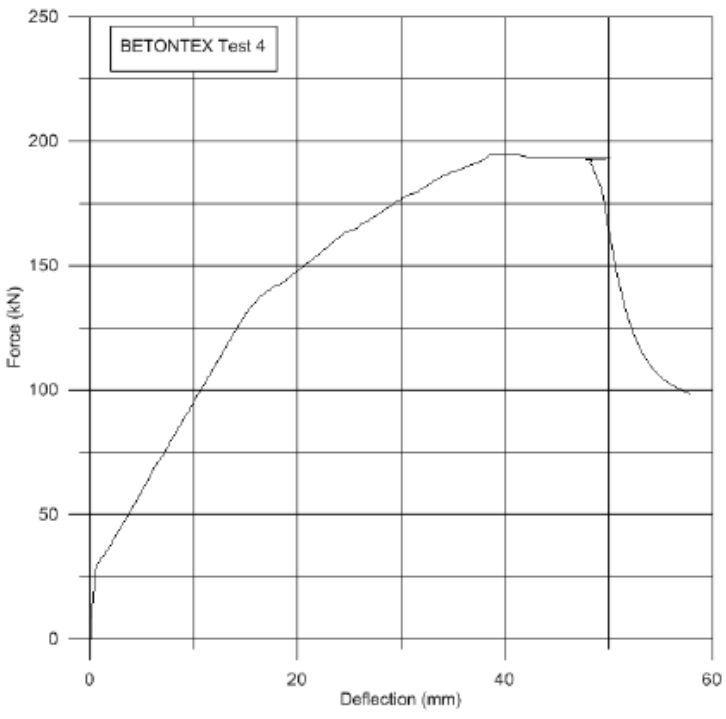

(b) Specimen 2

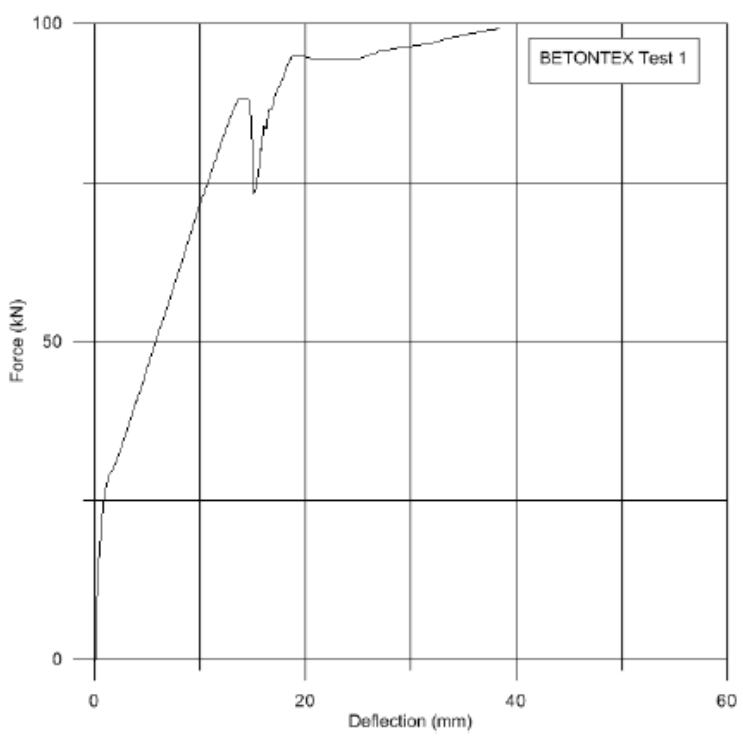

(d) Specimen 4

Fig. (6). Load-deflection curves for specimens 1, 2, 3 and 4, respectively.

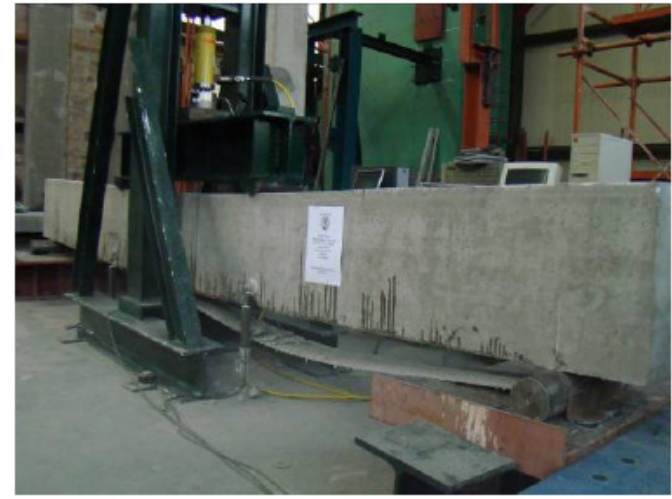

(a)

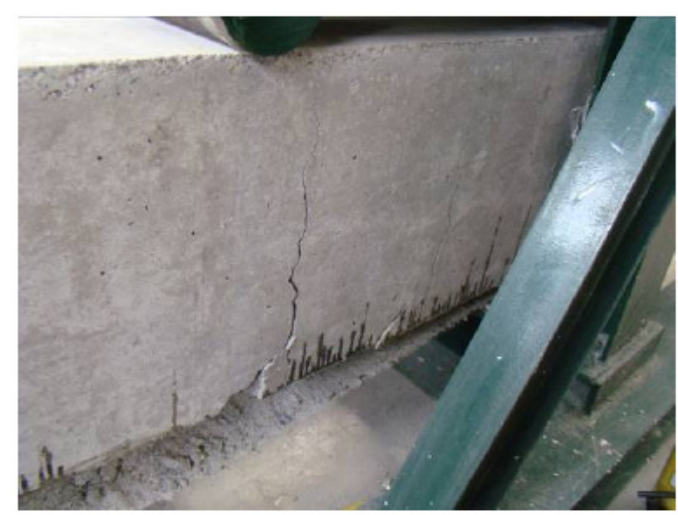

(b)

Fig. (7). Specimen 1 - (a) CFRP debonding along the beam length, and (b) Flexural cracks at mid-span. 


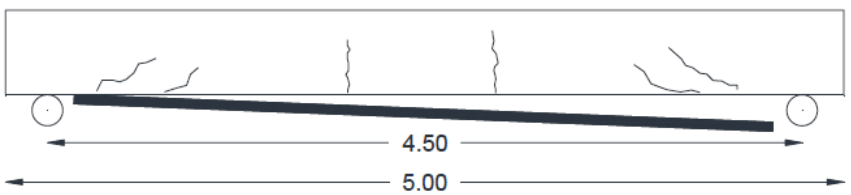

Fig. (8). Specimen 1 - Crack pattern at the end of test.

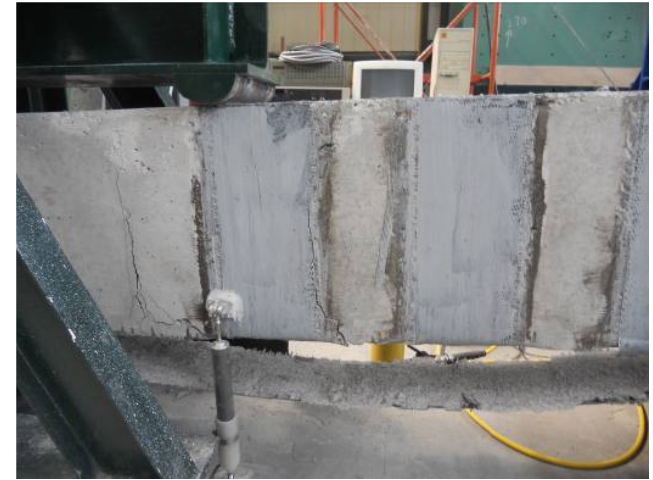

Fig. (9). Specimen 2 - Debonding of the CFRP strengthening system.

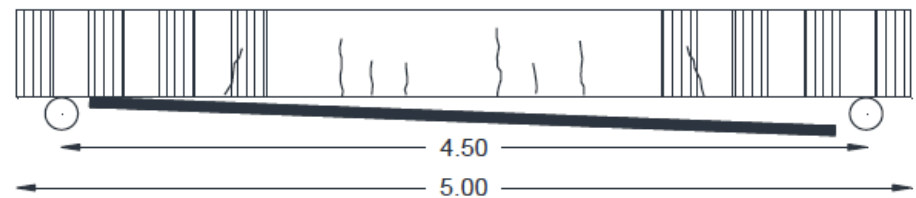

Fig. (10). Specimen 2: Crack pattern at the end of test.

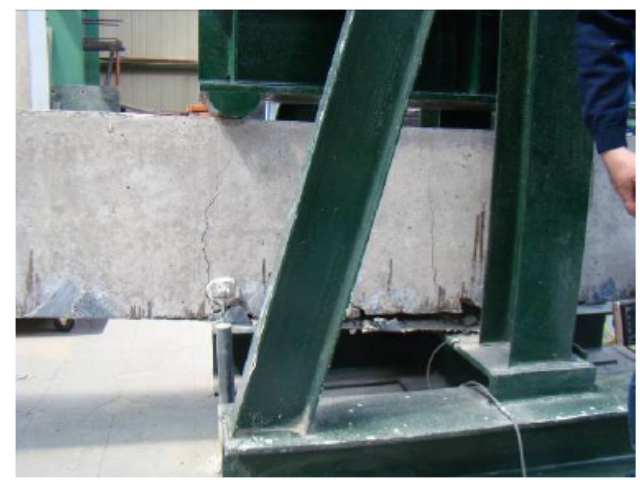

(a)

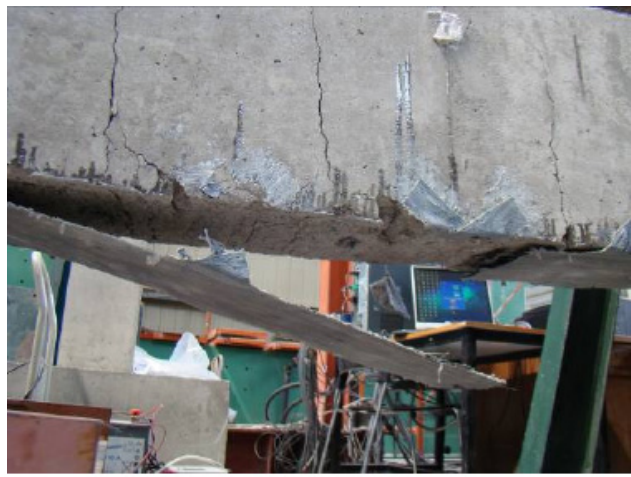

(b)

Fig. (11). Specimen 3 - (a) Flexural cracks at mid-span, and (b) rupture of CFRP strengthening system.

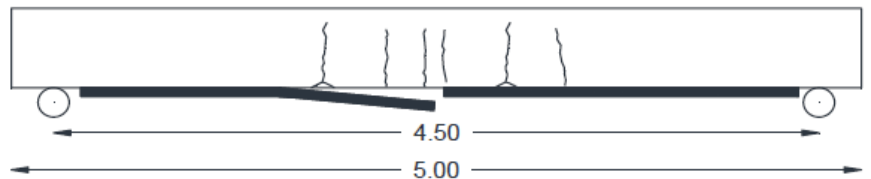

Fig. (12). Specimen 3 - Crack pattern at the end of test.

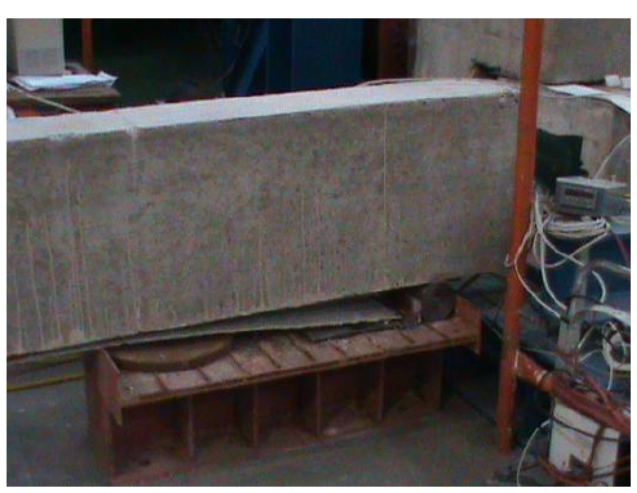

Fig. (13). Specimen 4- Debonding the CFRP sheets at the end of the test.

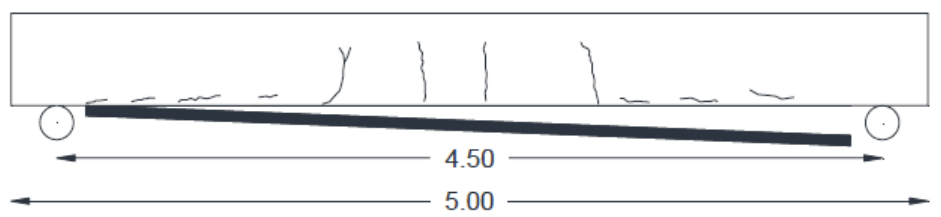

Fig. (14). Specimen 4 - Crack pattern at the end of the test. 
composite materials are analytically calculated, as anticipated by the load (F) causing failure to each one of the specimens. Consequently, an analysis was contacted and a comparison between the experimentally based values and the ones obtained according to the EC8-GARC.

\subsection{Analysis Procedure}

The analytical calculations refer to the force-equilibrium of the concrete beam strengthened with the CFRP system, as shown schematically in Fig. 15. In all calculations that follow the factors of safety are taken as equal to 1 .

The analytical procedure is presented only for the first specimen. The corresponding results for all the other specimens are presented in Table $\mathbf{5}$.

The load-deflection curve for specimen No 1 is shown in Fig. 6(a). From this curve, the measured force at failure is $\mathrm{F}$ $=181.45 \mathrm{kN}$ and from equilibrium, including the dead load of the beam, the corresponding flexural strength is obtained via equilibrium to be: $\mathrm{M}_{\mathrm{R}}=143.90 \mathrm{kNm}$.

Applying an iterative analytical procedure (IAP) one can arrive at the following strains $\left(\varepsilon_{\mathrm{c}}, \varepsilon_{\mathrm{s} 1}, \varepsilon_{\mathrm{s} 2}, \varepsilon_{\mathrm{f}}\right)$ that fulfill the compatibility and equilibrium requirements at the section for $M_{R}=143.90 \mathrm{kNm}$, that is Notice that the elongation at failure caused by debonding of the composite material is $\varepsilon_{\mathrm{f}}=6.854 \%$.

\subsection{Calculations According to the Greek Assessment and Retrofitting Code}

According to the (EC8-GARC), failure of the strengthening material occurs when

$$
\begin{aligned}
& \sigma_{j, c r i t}=f_{j k} \\
& \sigma_{j d}=\frac{1}{\gamma_{m}} \cdot f_{j k}
\end{aligned}
$$

where $f_{j k}$ is the characteristic value of material strength and $\gamma_{m}$ is the factor of safety for the material.

Early debonding of the strengthening material because of inadequate bonding or inadequate anchorage at its edges occurs when

$$
\sigma_{j d}=\frac{1}{\gamma_{R d}} \cdot \sigma_{j, c r i t}
$$

where $\gamma_{R d}$ is the factor of safety that accounts for all the model uncertainties and $\sigma_{j, \text { crit }}$ is the material stress for debonding.

The design effective stress $\sigma_{\mathrm{jd}}$ of the CFRP reinforcement is estimated according to the critical stress $\sigma_{j, c r i t}$ and has to be smaller than the $\sigma_{\mathrm{jd}}$ corresponding to the worst of the following failure modes:

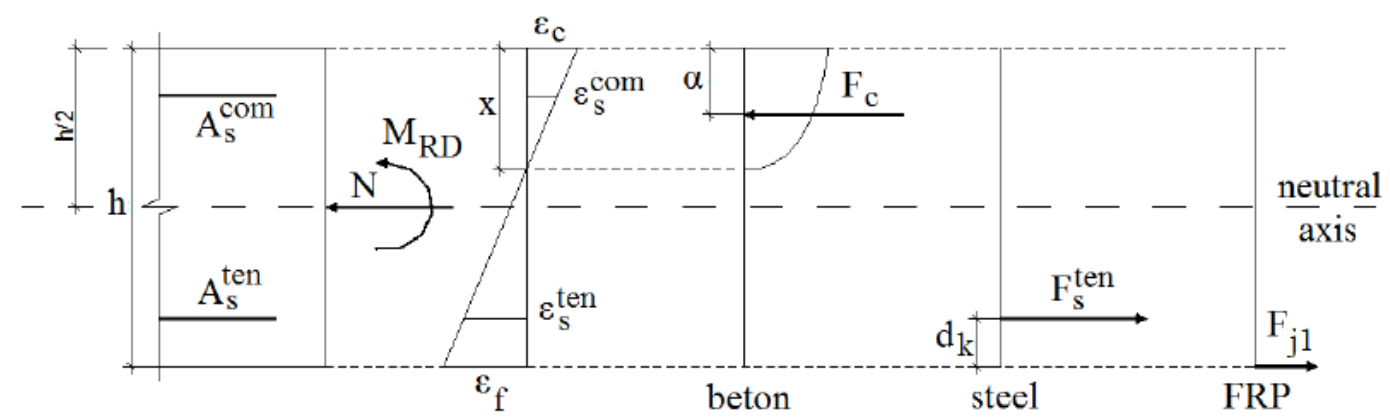

Fig. (15). Analysis of section subjected to bending.

$$
\begin{aligned}
& \varepsilon_{\mathrm{c}}=-1.690 \% \\
& \varepsilon_{\mathrm{f}}=6.854 \% \\
& \alpha=\left\{\begin{array}{c}
\frac{\varepsilon_{\mathrm{c}} \cdot\left(6-\varepsilon_{c}\right)}{12}, \varepsilon_{\mathrm{c}} \leq 0.002 \\
\frac{3 \cdot \varepsilon_{\mathrm{c}}-2}{3 \cdot \varepsilon_{\mathrm{c}}}, \varepsilon_{\mathrm{c}}>0.002
\end{array} \rightarrow \alpha=0.606\right. \\
& \zeta^{\prime}=\left\{\begin{array}{c}
\frac{8-\varepsilon_{c}}{4 \cdot\left(6-\varepsilon_{c}\right)}, \varepsilon_{\mathrm{c}} \leq 0.002 \\
\frac{\varepsilon_{\mathrm{c}} \cdot\left(3 \cdot \varepsilon_{\mathrm{c}}-4\right)+2}{2 \cdot \varepsilon_{\mathrm{c}} \cdot\left(3 \cdot \varepsilon_{\mathrm{c}}-2\right)}, \varepsilon_{\mathrm{c}}>0.002
\end{array} \rightarrow \zeta^{\prime}=0.366\right. \\
& x=\xi \cdot d=\frac{\varepsilon_{c}}{\varepsilon_{c}+\varepsilon_{s}^{t e n}} \cdot\left(h-d_{b}\right) \rightarrow x=9.89 \mathrm{~cm} \\
& \alpha=\zeta^{\prime} \cdot x \rightarrow \alpha=0.0362 m
\end{aligned}
$$




\section{a. Failure of the Composite Material}

The ultimate strain of the composite material is equal to $\varepsilon_{\mathrm{frp}, \mathrm{u}}=15 \%$.

Accordingly, the design effective stress of the CFRP reinforcement is equal to

$$
\sigma_{\mathrm{jd}}=\mathrm{f}_{\mathrm{jk}} / \gamma_{\mathrm{m}}=3500 \mathrm{MPa} \text {. }
$$

Employing the IAP, one can calculate the design moment $\mathrm{M}_{\mathrm{Rd}}$ according to EC8-GARC, that is:

Yielding a flexural strength: $\mathrm{M}_{\mathrm{Rd}}=220.11 \mathrm{kNm}$

\section{b. Debonding of the Composite Material}

This failure mode usually occurs simultaneously with the failure of concrete cover of the longitudinal reinforcement at the edge of the FRP sheets. The EC8-GARC suggests the following approximate relationships for this failure mode:

$$
\begin{aligned}
& \sigma_{j, c r} \cong \beta \frac{\tau_{b}^{\text {debond }}}{t_{j}} L_{e} \\
& \tau_{b}^{\text {debond }} \cong f_{c t m}=0.30 \cdot f_{c m}^{2 / 3}=2.210 \mathrm{MPa} \\
& L_{e}=\sqrt{\frac{E_{j} t_{j}}{2 f_{c t m}}}=166.41 \mathrm{~mm}
\end{aligned}
$$

$$
\begin{aligned}
& \varepsilon_{\mathrm{c}}=-3.500 \% \\
& \varepsilon_{\mathrm{f}}=13.743 \% \\
& \alpha=\left\{\begin{array}{l}
\frac{\varepsilon_{\mathrm{c}} \cdot\left(6-\varepsilon_{c}\right)}{12}, \varepsilon_{\mathrm{c}} \leq 0.002 \\
\frac{3 \cdot \varepsilon_{\mathrm{c}}-2}{3 \cdot \varepsilon_{\mathrm{c}}}, \varepsilon_{\mathrm{c}}>0.002
\end{array} \rightarrow \alpha=0.810\right. \\
& \zeta^{\prime}=\left\{\begin{array}{c}
\frac{8-\varepsilon_{c}}{4 \cdot\left(6-\varepsilon_{c}\right)}, \varepsilon_{\mathrm{c}} \leq 0.002 \\
\frac{\varepsilon_{\mathrm{c}} \cdot\left(3 \cdot \varepsilon_{\mathrm{c}}-4\right)+2}{2 \cdot \varepsilon_{\mathrm{c}} \cdot\left(3 \cdot \varepsilon_{\mathrm{c}}-2\right)}, \varepsilon_{\mathrm{c}}>0.002
\end{array} \rightarrow \zeta^{\prime}=0.416\right. \\
& x=\xi \cdot d=\frac{\varepsilon_{c}}{\varepsilon_{c}+\varepsilon_{s}^{t e n}} \cdot d \rightarrow x=10.15 \mathrm{~cm} \\
& \alpha=\zeta^{\prime} \cdot x \rightarrow \alpha=0.0422 m
\end{aligned}
$$

$$
\beta_{w}=\sqrt{\frac{2-w_{j} / b}{1+w_{j} / b}}=0.816
$$

$\beta_{L}=1.0$ (since $\mathrm{L}_{\mathrm{av}}=1750 \mathrm{~mm}>\mathrm{L}_{\mathrm{e}}=166.41 \mathrm{~mm}$ ), where $\mathrm{L}_{\mathrm{av}}$ and $\mathrm{L}_{\mathrm{e}}$ is the available and the required anchorage length, respectively. Thus,

$$
\begin{aligned}
& \beta=\beta_{w} \cdot \beta_{L}=0.816 \\
& \sigma_{j, c r}=588.784 \mathrm{MPa} \\
& \varepsilon_{j, c r}=\sigma_{j, c r} / E_{j}=2.453 \%
\end{aligned}
$$

Employing the IAP, the design moment $\mathrm{M}_{\mathrm{Rd}}$ according to EC8-GARC is obtained: $\mathrm{M}_{\mathrm{Rd}}=84.75 \mathrm{kNm}$

\section{c. Design Effective Stress $\sigma_{j d}$}

The CFRP reinforcement is calculated so that it can undertake, in cooperation with the existing reinforcement, the additional imposed moment. In order to calculate the required section of strengthening CFRP reinforcement $\left(A_{j}\right)$ the following approximate analytical expression can be used [20]:

$$
\begin{aligned}
& A_{j}=\frac{\Delta M_{d o}}{z \cdot \sigma_{j d}} \rightarrow \Delta \mathrm{M}_{d o}=\sigma_{j d} \cdot z \cdot A_{j} \\
& \mathrm{z}=0,9 \cdot\left(\mathrm{h}-\mathrm{d}_{\mathrm{b}}\right)=41.85 \mathrm{~cm} \\
& \varepsilon_{\mathrm{s}}{ }^{\mathrm{com}}=-2.293 \% \mathrm{o} \rightarrow \mathrm{f}_{\mathrm{s}}^{\mathrm{com}}=458.60 \mathrm{MPa} \\
& \varepsilon_{\mathrm{s}}{ }^{\text {ten }}=12.536 \% \mathrm{o} \rightarrow \mathrm{f}_{\mathrm{s}}^{\text {ten }}=500.00 \mathrm{MPa} \\
& \mathrm{F}_{\mathrm{c}}=\alpha \cdot 0.85 \cdot \mathrm{f}_{\mathrm{cd}} \cdot \mathrm{x} \cdot \mathrm{b} \rightarrow \mathrm{Fc}=349.18 \mathrm{kN} \\
& \mathrm{F}_{\mathrm{s}}{ }^{\mathrm{com}}=\mathrm{A}_{\mathrm{s}}^{\mathrm{com}} \cdot \mathrm{f}_{\mathrm{s}}^{\mathrm{com}}=141.19 \mathrm{kN}(\text { compression }
\end{aligned}
$$
steel)

$\mathrm{F}_{\mathrm{s}}^{\text {ten }}=\mathrm{A}_{\mathrm{s}}^{\text {ten }} \cdot \mathrm{f}_{\mathrm{s}}^{\text {ten }}=153.94 \mathrm{kN}($ tension steel)

$\mathrm{F}_{\mathrm{j} 1}=\varepsilon_{\mathrm{f}} \cdot \mathrm{E}_{\mathrm{j}} \cdot \mathrm{n}_{\mathrm{j}} \cdot \mathrm{t}_{\mathrm{j}} \cdot \mathrm{w}_{\mathrm{j}}=336.43 \mathrm{kN}$ (tension composite)

$\mathrm{F}_{\mathrm{c}}+\mathrm{F}_{\mathrm{s}}^{\mathrm{com}}-\mathrm{F}_{\mathrm{s}}^{\text {ten }}-\mathrm{F}_{\mathrm{j} 1}=0$

$\mathrm{M}_{\mathrm{R}}=\mathrm{F}_{\mathrm{c}}(0.5 \mathrm{~h}-\mathrm{a})+\mathrm{F}_{\mathrm{j} 1} 0.5 \mathrm{~h}+\mathrm{F}_{\mathrm{s}}^{\text {ten }}\left(0.5 \mathrm{~h}-\mathrm{d}_{\mathrm{b}}\right)+\mathrm{F}_{\mathrm{s}}{ }^{\mathrm{com}}$ $\left(0.5 \mathrm{~h}-\mathrm{d}_{\mathrm{t}}\right)=220.11 \mathrm{kNm}$

Table 5. Experimental values (F) and corresponding values $\left(M_{R d}, \varepsilon_{f}, \sigma_{j}\right)$ for specimens 1, 2, 3 and 4 .

\begin{tabular}{|c|c|c|c|}
\hline Specimen 1 & Specimen 2 & Specimen 3 & Specimen 4 \\
\hline \hline $\mathrm{F}=181.45 \mathrm{kN}$ & $\mathrm{F}=191.82 \mathrm{kN}$ & $\mathrm{F}=213.50 \mathrm{kN}$ & $\mathrm{F}=98.26 \mathrm{kN}$ \\
\hline $\mathrm{MR}=143.90 \mathrm{kNm}$ & $\mathrm{MR}=151.68 \mathrm{kNm}$ & $\mathrm{MR}=167.94 \mathrm{kNm}$ & $\mathrm{MR}=81.51 \mathrm{kNm}$ \\
\hline$\varepsilon \mathrm{f}=6.854 \% 0$ & $\varepsilon \mathrm{f}=7.538 \% 0$ & $\varepsilon \mathrm{f}=8.993 \% 0$ & $\sigma \mathrm{f}=567.120 \mathrm{MPa}$ \\
\hline$\sigma \mathrm{j}=1644.960 \mathrm{MPa}$ & $\sigma \mathrm{j}=1809.120 \mathrm{MPa}$ & $\sigma \mathrm{j}=2158.320 \mathrm{MPa}$ & \\
\hline
\end{tabular}




\section{a. Failure of the Composite Material}

Effective Stress: $\sigma_{\mathrm{jd}}=3500 \mathrm{MPa}$.

Flexural Strength: $\Delta \mathrm{M}=149.40 \mathrm{kNm}$

\section{b. Early Debonding of the Composite Material}

Effective Stress: $\sigma_{\mathrm{jd}}=588.784 \mathrm{MPa}$.

Flexural Strength: $\Delta \mathrm{M}=25.13 \mathrm{kNm}$

A comparison between the results for the four specimens is presented in Table $\mathbf{5}$.

Comparing the results for the four specimens, it can be seen that there is a significant difference in the flexural strength of the beam for bonding the FRP fabric with epoxy $\mathrm{RC}$ resin, epoxy $\mathrm{RC}$ resin with U-Shape ties, epoxy $\mathrm{RC}$ resin with ARDFIX connectors and IPN resin.

Application of the connectors, in this case at a distance of $40 \mathrm{~cm}$, has significantly increased the flexural strength of the beam, that is, about $76.0 \%$ of the maximum flexural strength corresponding to failure of the FRP fibers in tension.

For specimen 4, where the IPN resin was applied, a substantial difference is observed when the results are compared with specimen 1. Nevertheless, consequent experience has shown that proper wetting and roughening of the contact area can increase the adhesion of IPN resin to the concrete substrate, so that the elongation at failure from debonding may well exceed $3 \%$.

Table 6 presents the design values according to the (EC8GARC) and Table 7 shows the test result for tha cubic specimens.

Table 6. Design values according to the (EC8-GARC).

\begin{tabular}{|c|c|}
\hline (EC8-GARC)- (IAP) & $\left(\right.$ EC8-GARC) $-\Delta M_{d 0}=\sigma_{\mathrm{jd}} \cdot \mathbf{z} \cdot \mathbf{A}_{\mathrm{j}}$ \\
\hline a. Failure of the & a. Failure of the \\
\hline Composite Material: & Composite Material: \\
\hline$\varepsilon \mathrm{frp}, \mathrm{u}=15 \%$ & $\varepsilon \mathrm{frp}, \mathrm{u}=15 \%$ \\
\hline$\sigma \mathrm{jd}=3500 \mathrm{MPa}$ & $\sigma \mathrm{jd}=3500 \mathrm{MPa}$ \\
\hline Flexural Strength: & Flexural Strength: \\
\hline $\mathrm{MRd}=220.11 \mathrm{kNm}$ & $\mathrm{MRd}=149.40 \mathrm{kNm}$ \\
\hline b. Early Debonding of & b. Early Debonding of \\
\hline the Composite Material: & the Composite Material: \\
\hline$\varepsilon \mathrm{frp}, \mathrm{u}=2.453 \% 0$ & $\varepsilon \mathrm{frp}, \mathrm{u}=2.453 \% 0$ \\
\hline$\sigma \mathrm{j}, \mathrm{cr}=588.784 \mathrm{MPa}$ & $\sigma \mathrm{j}, \mathrm{cr}=588.784 \mathrm{MPa}$ \\
\hline Flexural Strength: & Flexural Strength: \\
\hline $\mathrm{MRd}=84.75 \mathrm{kNm}$ & $\mathrm{MRd}=25.13 \mathrm{kNm}$ \\
\hline
\end{tabular}

Comparing the results of the four specimens with the ones calculated according to the (EC8-GARC), see Table 6, it can be stated that: when the controlling failure is debonding, the calculated flexural strength is much lower (less than
$1 / 3$ ) than the one deducted from the measurements for all of the tests with Epoxy RC resin, and close to the one calculated only in specimen 4 for which the IPN was used. This clearly indicates that the EC8-GARC is very conservative, rendering a value that is about $(41 \%)$ or $(83 \%)$ less than the experimentally determined value when using the IAP or the approximate $\Delta \mathrm{M}_{\mathrm{do}}$ expression, respectively.

When calculations according to the approximate analytical expression $\Delta \mathrm{M}_{\mathrm{do}}=\sigma_{\mathrm{jd}} \cdot \mathbf{Z} \cdot \mathrm{A}_{\mathrm{j}}$ are performed, for either failure or early debonding of the composite material, it is observed that the calculated flexural strength substantially differs with the ones obtained according to the IAP, which means that the (EC8-GARC) expression is very conservative.

In order to provide valuable measurements for the design process, pull-out tests were conducted in order to measure the debonding stress, $\tau_{b}^{d e b o n d}$. Specifically, six cubic specimens were constructed (three with IPN and three with epoxy $\mathrm{RC}$ resin) and three pull-out tests were conducted for each one of them, as shown in Fig. 16.

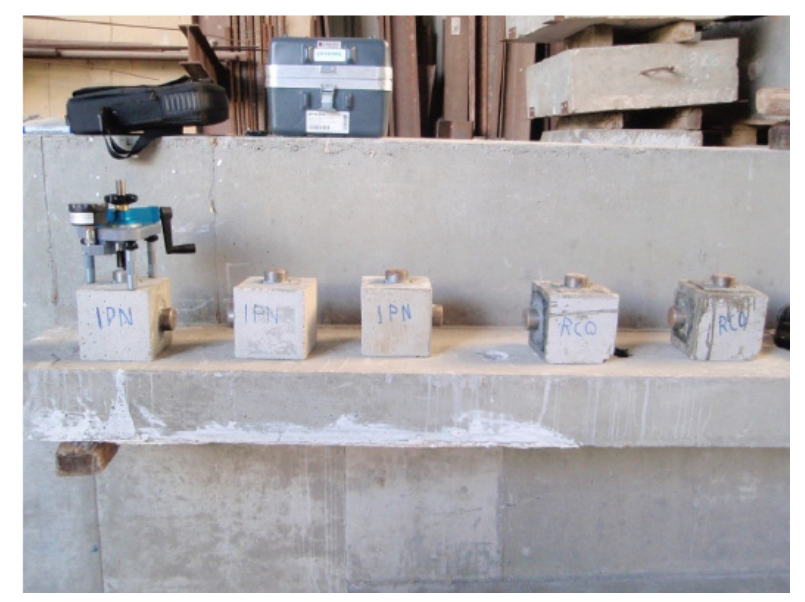

Fig. (16). Cubic specimens for pull-out tests.

Table 7. Tests Results for the Cubic Specimens.

\begin{tabular}{|l|l|}
\hline Resin IPN & Epoxy Resin RC \\
a) $1^{\text {st }}$ Cubic Specimen & a) $4^{\text {th }}$ Cubic Specimen \\
$1^{\text {st }}$ test: $2.97 \mathrm{MPa}$ & $1^{\text {st }}$ test: $1.77 \mathrm{MPa}$ \\
$2^{\text {nd }}$ test: $2.66 \mathrm{MPa}$ & $2^{\text {nd }}$ test: $3.56 \mathrm{MPa}$ \\
$3^{\text {rd }}$ test: $2.37 \mathrm{MPa}$ & $3^{\text {rd }}$ test: $1.40 \mathrm{MPa}$ \\
b) $2^{\text {nd }}$ Cubic Specimen & b) $5^{\text {th }}$ Cubic Specimen \\
$1^{\text {st }}$ test: $2.21 \mathrm{MPa}$ & $1^{\text {st }}$ test: $4.05 \mathrm{MPa}$ \\
$2^{\text {nd }}$ test: $2.98 \mathrm{MPa}$ & $2^{\text {nd }}$ test: $1.11 \mathrm{MPa}$ \\
$3^{\text {rd }}$ test: $2.60 \mathrm{MPa}$ & $3^{\text {rd }}$ test: $1.47 \mathrm{MPa}$ \\
c) $3^{\text {rd }}$ Cubic Specimen & c) $6^{\text {th }}$ Cubic Specimen \\
$1^{\text {st }}$ test: $2.38 \mathrm{MPa}$ & $1^{\text {st }}$ test: $2.81 \mathrm{MPa}$ \\
$2^{\text {nd }}$ test: $2.60 \mathrm{Mpa}$ & $2^{\text {nd }}$ test: $2.85 \mathrm{MPa}$ \\
$3^{\text {rd }}$ test: $2.03 \mathrm{MPa}$ & $3^{\text {rd }}$ test: $1.77 \mathrm{MPa}$ \\
Mean Value of Debonding Stress: & Mean Value of Debonding Stress: \\
$\mathbf{2 . 5 3} \mathbf{M P a}$ & $\mathbf{2 . 3 1}$ MPa \\
\hline
\end{tabular}

Table 8 presents the $\tau_{b}^{\text {debond }}$ obtained from (EC8-GARC) and the mean debonding stresses from the pull -out tests, as well as the anchor length $L_{e}$, the critical stress correspond- 
Table 8. Comparative Table of Results for the cubic specimens pull-out tests.

\begin{tabular}{|c|c|c|c|}
\hline & Greek Assessment and Retrofitting Code & Cubic pull-out tests Resin IPN & Cubic pull-out tests Epoxy Resin RC \\
\hline \hline$\tau_{b}^{\text {debond }}$ & $2.21 \mathrm{MPa}$ & $2.53 \mathrm{MPa}$ & $2.31 \mathrm{MPa}$ \\
\hline $\mathrm{L}_{\mathrm{e}}=\sqrt{\frac{\mathrm{E}_{\mathrm{j}} \cdot \mathrm{t}_{\mathrm{j}}}{2 \cdot \mathrm{f}_{\mathrm{ctm}}}<\mathrm{L}_{\mathrm{av}}}$ & $166.41 \mathrm{~mm}$ & $155.53 \mathrm{~mm}$ & $162.77 \mathrm{~mm}$ \\
\hline$\sigma_{\mathrm{j}, \mathrm{cr}} \cong \beta \frac{\tau_{\mathrm{b}}^{\text {debond }}}{\mathrm{t}_{\mathrm{j}}} \mathrm{L}_{\mathrm{e}}$ & $588.784 \mathrm{MPa}$ & $629.970 \mathrm{MPa}$ & $601.958 \mathrm{MPa}$ \\
\hline$\varepsilon_{\mathrm{j}, \mathrm{cr}}$ & $2.453 \% 0$ & $2.625 \% \mathrm{o}$ & $2.508 \%$ \\
\hline$\Delta \mathrm{M}_{\mathrm{do}}=\sigma_{\mathrm{j}} \cdot \mathrm{z} \cdot \mathrm{A}_{\mathrm{j}}$ & $25.13 \mathrm{kNm}$ & $26.89 \mathrm{MPa}$ & $25.70 \mathrm{MPa}$ \\
\hline $\mathrm{IAP}$ & $84.75 \mathrm{kNm}$ & $90.82 \mathrm{kNm}$ & $86.65 \mathrm{kNm}$ \\
\hline
\end{tabular}

ing to the debonding failure stress $\sigma_{j, c r}$ and the flexural strength corresponding to debonding failure for both the (EC8-GARC) provisions and the IAP.

Comparing the calculated debonding stress $\tau_{b}^{\text {debond }}$ according to the (EC8-GARC) with the one obtained from the pull-out tests to the cubic specimens, it can be stated that the calculations according to [22] are close to the ones obtained from the tests. Nevertheless, it should be common practice to perform pull-out tests as specified in pertinent codes, e.g., ref. [20].

Also comparison between the $\mathrm{M}_{\mathrm{R}}$ and $\Delta \mathrm{M}_{\mathrm{do}}$ the from Table 6 and $\mathbf{8}$, respectively, it is observed that the flexural strength calculated according to the EC8-GARC is always much lower than the one resulting from the experiments, indicating that the code is conservative. However, for the specimen 4, the experiment and EC8-GARC yield practically identical flexural strengths.

\section{CONCLUSION}

Based on the results presented herein, the following conclusions can be drawn:

- The CFRP application led to an increase of the beam strength and stiffness. Although all specimens were reinforced with identical layers of CFRP, it was observed that different resin and anchorage systems significantly influenced the resulting strength and stiffness of the specimens. The best results were achieved with connectors.

- The results of the experiments have verified that: the code [20] evaluated increase in bending strength is substantially underestimated, when delamination is the mode of failure.

- All tests verified a common design practice, that is, a minimum strain of $3 \%$ at failure can be considered in design even with the presence of a minimum number of anchors. This is an observation of particular importance in avoiding overdesign of CFRP strengthened structural members in bending. Nevertheless, such a practice should always be accompanied by in-situ pull-out testing.
- Regarding the EC8-GARC code, the experimental and analytical work demonstrated that: a) the debonding stress $\tau_{b}^{\text {debond }}$ calculated according to the EC8-GARC is quite accurate, b) when debonding is the mode of failure, the strength calculated with the analytical models proposed by the Code [22] are conservative, and c) the approximate analytical expression $\Delta \mathrm{M}_{\mathrm{do}}=\sigma_{\mathrm{jd}} \cdot \mathrm{z} \cdot \mathrm{A}_{\mathrm{j}}$ of the Code is, by no means an accurate analytical expression, greatly underestimating the increase achieved by the CFRP reinforcement.

- The recommended practice would be to perform in-situ pull-out tests, calculate the strength through satisfaction of equilibrium and compatibility requirements, that is use of the IAP, and installation of a minimum number of anchors.

- Spacing of anchors in the range of $2 / 3^{\text {rds }}$ of the beam height led to dramatically higher debonding strains; thus, allowing a more efficient use or the CFRP reinforcement. However, more research is needed in order to assess the effect of anchoring systems and arrive at well documented design recommendations.

\section{CONFLICT OF INTEREST}

The authors confirm that this article content has no conflict of interest.

\section{ACKNOWLEDGEMENTS}

The FRP were provided by BETONTEX ${ }^{\circledR}$ and the application of the strengthening material was performed under the supervision of technical personnel of the company.

\section{REFERENCES}

[1] J. G. Teng, H. Yuan, and J. F. Chen, "FRP-to-concrete interfaces between two adjacent cracks: Theoretical model for debonding failure", International Journal of Solids \& Structures, vol. 43, pp. 5750-78, 2006

[2] K. V. Subramaniam, C. Carloni, and L. Nobile, "Width effect in the interface fracture during shear debonding of FRP sheets from concrete", Engineering Fracture Mechanics, vol. 74, pp. 578-94, 2007.

[3] F. Chen, and P. Qiao, "Debonding analysis of FRP-concrete between two balanced adjacent flexural cracks in plated beams", In- 
ternational Journal of Solids \& Structures, vol. 46, pp. 2618-28, 2009.

[4] J. F. Chen, H. Yuan, and J. G. Teng, "Debonding failure along a softening FRP-to-concrete interface between two adjacent cracks in concrete members", Engineering Structures, vol. 29, pp. 259-270, 2007.

[5] O. Gunes, O. Buyukozturk, and E. Karaka, "A fracture-based model for FRP debonding in strengthened beams", Engineering Fracture Mechanics, vol. 76, pp. 1897-909, 2009.

[6] L. Ombres, "Prediction of intermediate crack debonding failure in FRP-strengthened reinforced concrete beams", Composite Structures, vol. 92, pp. 322-329, 2010.

[7] K. Benzarti, F. Freddi, and M. Frémond, "A damage model for predicting the durability of bonded assemblies. Part I: Debonding behavior of FRP strengthened concrete members", Construction \& Building Materials, vol. 25, pp. 547-55, 2011.

[8] F. Ceroni, M. Pecce, S. Matthys, and L. Taerwe, "Debonding strength and anchorage devices for reinforced concrete elements strengthened with FRP sheets", Composites Part: B, vol. 39, pp. 429-41, 2008.

[9] D. Bruno, R. Carpino, and F. Greco, "Modeling of mixed mode debonding in externally FRP reinforced beams", Composite Science \& Technology, vol. 67, pp. 1459-1474, 2007.

[10] J. R. Casas, and J. Pascual, "Debonding of FRP in bending: Simplified model and experimental validation", Construction \& Building Materials, vol. 21, pp. 1940-1949, 2007.

[11] P. Alagusundaramoorthy, I. E. Harik, and C. C. Choo, "Flexural behavior of R/C beams strengthened with Carbon Fiber Reinforced Polymer Sheets or Fabric", Journal of Composites for Construction, vol. 7, No. 4, pp. 292-301, 2003.

[12] K. Takeda, Y. Mitsui, K. Murakami, H. Sakai, and M. Nakamura, "Flexural Behavior of reinforced concrete beams strengthened with Carbon Fiber sheets", Composites Part A, vol. 27, No. A, pp. 981987, 1996.
[13] H. S. Kim, and Y. S. Shin, "Flexural behavior of Reinforced Concrete (RC) beams retrofitted with Hybrid Fiber Reinforced Polymers (FRPs) under sustaining loads", Composite Structures, vol. 93, pp. 802-811, 2011.

[14] T. Norris, "Flexural behavior of Reinforced Concrete (RC) Beams retrofitted with hybrid fiber reinforced polymers (FRPs) under sustaining loads", Journal of Structural Engineering, vol. 123, No. 7, pp. 903-911, 1997.

[15] C. B. Demakos, and G. Dimitrakis, "On the Effect of FRP Sheet Composite Anchorage to Flexural Behavior of Reinforced Concrete Beams", in Proceedings of Excellence in Concrete Construction through Innovation, 2009, pp. 345-355.

[16] C. B. Demakos, C. C. Repapis, and D. Drivas, "Investigation of structural response of reinforced concrete beams strengthened with anchored FRPs", The Open Construction and Building Technology Journal, vol. 7, pp. 146-57, 2013.

[17] C. C. Spyrakos, "Structural Strengthening for Seismic Loads," (in Greek), Athens: Technical Chamber of Greece (T.E.E.), 2004.

[18] D. Gay, S. V. Hoa, and S. W. Tsai, "Composite Materials Design and Applications," Boca Raton: CRC PRESS, 2002.

[19] ACI 440.3R - 04, "Guide Test Methods for Fiber-Reinforced Polymers (FRPs) for reinforcing or strengthening concrete structures", Reported by ACI Committee 440, 2004

[20] International Federation for Structural Concrete (FIB). "Externally Bonded FRP Reinforcement for RC Structures - Bulletin 14", July, 2001.

[21] Consiglio Nazionale Delle Ricerche. Instruzioni per la Progettazione, l' Esecuzione ed il Controllo di Interventi di Consolidamento Statico mediante 1' utillizzo di Compositi Fibrorinforzati, CNR-DT 200/2004.

[22] Earthquake Planning and Protection Organization. Eurocode 8 Greek Assessment and Retrofitting Code (EC8-GARC), Jan. 2012.

(C) Spyrakos et al.; Licensee Bentham Open.

This is an open access article licensed under the terms of the Creative Commons Attribution Non-Commercial License (http://creativecommons.org/licenses/by-nc/3.0/) which permits unrestricted, non-commercial use, distribution and reproduction in any medium, provided the work is properly cited. 